\title{
The Complex Problem of Women Trainees in Academic Medicine
}

\author{
Bridget Keenan, MD, PhD ${ }^{1 *}$; Lekshmi Santhosh, MD²; Vanessa Thompson, MD³; Elizabeth Harleman, $\mathrm{MD}^{3}$
}

'Division of Hematology/Oncology, Department of Medicine, University of California, San Francisco, California; ${ }^{2}$ Division of Pulmonary and Critical Care Medicine, Department of Medicine, University of California, San Francisco, California; ${ }^{3}$ Department of Medicine, University of California, San Francisco, California.

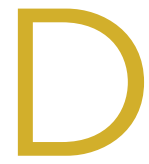

espite media attention to gender inequality in multiple professions, medicine has only recently begun to identify disparities facing women in academic medicine, focusing primarily on women faculty rather than trainees. Because of the unique and poorly understood juxtaposition of forces affecting their experience, focusing on women medical trainees may provide a representative framework to understand the larger, complex problem of gender equity in medicine. Rather than being a complicated problem with component parts that can be separately addressed, gender equity in medicine is a complex problem-one composed of a myriad of interrelated human and systemic factors. Such a complex problem demands innovative, open-minded, user-centered interventions. Here, we outline some of the factors unique to women trainees, including lack of female role models in leadership, gender bias, sexual harassment, work-life imbalance, and few formal leadership training programs. We propose one potential strategy, leadership programs specifically targeted to women residents and fellows. We recently implemented this strategy at our institution in the form of a day-long symposium of skill-building sessions for women residents and fellows.

Although women have achieved equal representation in several medical training programs, there is still a dearth of women in high-profile leadership positions within academic medicine. Although women comprised $46 \%$ of United States medical school applicants and residents in 2015-2016, underrepresentation persists at the level of associate professor (35\% women), full professor (22\%), department chair (14\%), and dean (16\%). ${ }^{1}$ Many potential women leaders may not self-identify as such due to the limited exposure to women role models in positions of power and may in fact be ready for leadership roles earlier but not apply until later in their careers as compared with men. ${ }^{2,3}$ The lack of role models with a shared background is an even more severe problem for women of color and all of these factors contribute to the "leaky pipeline" phenomenon. ${ }^{4}$ We aimed to address this mindset and help women see themselves as leaders by overcoming "second-generation gender bias" through our work. ${ }^{2}$ *Corresponding Author: Bridget Keenan, MD, PhD; E-mail: Bridget.keenan@
ucsf.edu; Telephone: (415) 514-0269; Twitter: @bridgetMDPhD

Received: August 22, 2018; Revised: November 17, 2018;

Accepted: November 26, 2018

(๔ 2019 Society of Hospital Medicine DOI 10.12788/jhm.3131
Due to the intense and inflexible nature of residency and fellowship training programs, many women choose to defer milestones such as childbearing. ${ }^{5}$ Women trainees are more likely than their male colleagues to avoid having a child during residency due to perceived threat to their career and negative perceptions of colleagues. 5,6 Women who are in a domestic partnership often bear the brunt of the household work regardless of the careers of the two partners, a phenomenon termed the "second shift." ${ }^{\text {" }}$ This work-life imbalance has been shown to correlate with depressive symptoms in women internal medicine trainees. ${ }^{8}$

Recently, a trainee published on the experience of medical residents being asked whether they were ever called "nurse." All the women in the room put up their hands; none of their male colleagues did. ${ }^{9}$ At issue is not the relative importance of the professions of medicine and nursing, but rather the gender stereotypes in medicine that lead to automatic categorization of women into one group. Although the majority of women residents likely have had personal experiences with bias and microaggressions, few are explicitly taught the tools to address these. Beyond microaggressions, women trainees are also subject to more sexual harassment than their male colleagues. ${ }^{10}$ In addition, women living at the intersections of race, ethnicity, and gender are faced with even higher rates of harassment. ${ }^{11}$ Reporting sexual assault and harassment can be particularly difficult as a trainee because of the risk of retaliation, fear of poor evaluations from superiors, and lack of confidence in the reporting process. ${ }^{10}$

Finally, women trainees often receive little training about the skills required for career advancement to achieve parity with their male colleagues. Women are less likely to negotiate due to concerns about backlash or due to general lack of awareness about the importance of negotiation. ${ }^{12}$ Women are asked to volunteer for "nonpromotable" tasks more often than men by colleagues of both sexes, a barrier to women reaching their full career potential and a difficult workplace scenario to navigate..$^{13}$ Unlike the fields of business, law, and technology, for example, women in medicine do not routinely have training courses that incorporate skills such as navigating difficult conversations, conflict resolution, curriculum vitae writing, and negotiation. Various solutions have been offered to address some of the barriers facing women in medicine (such as the Association of American Medical Colleges and Executive Leadership in Academic Medicine leadership courses), but typically these focus on faculty rather than trainees. Given that women physicians practicing in the inpatient setting have been shown 
to have better patient outcomes ${ }^{14}$ and organizations with female leadership outperform those led by men, ${ }^{15}$ equipping our women trainees to thrive in the clinical and leadership environments is an essential step in fulfilling our mission as high-quality training programs.

At our institution, we recognized the need for training in leadership skills for women medical trainees and designed a day-long symposium for internal medicine women residents and fellows. Before developing the curriculum, we conducted a needs assessment to ascertain which skills women wanted to develop; women overwhelmingly wanted to learn about public speaking skills, work-life integration, and mentoring. Based on these responses, a group spanning multiple levels of training (residency, fellowship, and faculty) designed a combination of large-group lectures and small-group workshops termed "Women in Leadership Development" (WILD). The day-long curriculum included sessions on public speaking skills, women as change agents, mentorship, conflict resolution, and addressing microaggressions and concluded with a networking event for women faculty and trainees (Table).

In total, 77 medicine residents and fellows voluntarily participated in the symposium in 2017 and 2018. The public speaking skills session received the highest reviews, with $98 \%$ of participants reporting that they identified ways to change public speaking styles to project confidence. This session was facilitated by an outside consultant in public speaking, highlighting the benefit of seeking experts outside of academic medicine. Another novel session focused on responding to microaggressions, defined as subtle and sometimes unintentional actions that express prejudice toward marginalized groups, in the clinical and academic environments. Microaggressions can undermine the recipient's confidence, feeling of belonging, and effectiveness at work. ${ }^{16}$ At our institution, trainees in graduate medical education report the largest single source of microaggressions as patients (greater than attendings, fellow trainees, or staff), with gender bias being responsible for the greatest number of microaggressions (Schaeffer, unpublished data). Navigating these situations to ensure good patient care and strong patient-provider relationships, while also establishing a climate of mutual respect, can be challenging for all women physicians, in particular for trainees who are just beginning to experience the clinical environment independently. Our session on microaggressions was purposefully led by a national expert in patient-provider communication and offered an opportunity for women trainees to reflect on their past experiences being the target of microaggressions, to name them as such, and then to brainstorm possible responses as a group. The result was a "toolkit" of resources for responding to microaggressions. ${ }^{17}$

Of the attendees of WILD 2017 and 2018, 91\% strongly agreed that participation in the symposium was a useful experience. One attendee reflected that they "feel more empowered to discuss women-related issues in academics with peers, mentors, mentees" and another stated that as a result of WILD, they would "sponsor peers and mentors, speak out more about gender bias, seek out leadership positions." Challenges for our symposium included obtaining protected
TABLE. WILD Symposium Agendaa

\begin{tabular}{ll}
\hline Topic & Core Competency \\
\hline Introduction to Issues Facing Women in Medicine & $\begin{array}{l}\text { Shaping Leadership Identity } \\
\text { Advocacy and Empowerment }\end{array}$ \\
\hline "Culture Box" Group Share & Community Building \\
\hline "Honing Your Voice as a Leader" Public Speaking Seminar & $\begin{array}{l}\text { Leadership Skills } \\
\text { Shaping Leadership Identity }\end{array}$ \\
\hline Women as Change Agents in Academic Medicine & Advocacy and Empowerment \\
\hline "Advocacy in Action" Brainstorming Session & Advocacy and Empowerment \\
\hline Peer Networking Lunch & Community Building \\
\hline Addressing Microaggressions and Ally Skill Building & Leadership Skills \\
\hline Building your Mentorship Team & Mentoring and Sponsorship \\
\hline Navigating Difficult Conversations and Conflict & Leadership Skills \\
\hline Mentor/Mentee Relationships Panel & Mentoring and Sponsorship \\
\hline Networking with Faculty Reception & $\begin{array}{l}\text { Community Building } \\
\text { Mentoring and Sponsorship }\end{array}$ \\
\hline
\end{tabular}

aSessions for the WILD Symposium are listed under "Topic." The corresponding core competencies that each "Topic" item fulfills are listed under "Core Competency."

curricular time from busy trainee schedules. Supportive leadership at all levels was critical to our success; carving out dedicated curricular time will be essential for the sustainability of this leadership symposium. Our group has recently received funding to expand to a longitudinal course open to all women residents and fellows across graduate medical education.

Although the complex and unique problems facing women medical trainees are unlikely to be comprehensively addressed by a leadership course, we urge other institutions to adopt and expand on our model for teaching vital leadership skills. In addition to leadership skills, academic medical centers should adopt a multipronged approach to support their female trainees, including clear and confidential reporting practices of sexual harassment without fear of retaliation, training for all staff on harassment and bias, involvement of men as allies, and mentorship programs for women trainees. Further research is needed to better understand this complex problem, its impact on career outcomes, and a path to achieving gender equality in medicine.

\section{Acknowledgments}

The authors are indebted to Catherine Lucey, MD, for her framing of the issues for women in medicine as a complex problem and to Sarah Schaeffer, MD, for her unpublished data on microaggressions at our institution. The authors are also grateful to the UCSF Department of Medicine and the UCSF Chancellor's Advisory Committee on the Status of Women for their financial support of the WILD (Women In Leadership Development) program.

Disclosures: The authors declare no conflict of interest

Funding: The authors report no external funding source for this study. 


\section{References}

1. AAMC [website]. 2018. https://www.aamc.org/. Accessed May 5, 2018

2. Ibarra H, Ely, Robin J, Kolb D. Women rising: the unseen barriers. Harvard Bus Rev. 2013;91(9):60-66.

3. Stevenson EJ, Orr E. We interviewed 57 female CEOs to find out how more women can get to the top. Harvard Bus Rev. 2017.

4. Mahoney MR, Wilson E, Odom KL, Flowers L, Adler SR. Minority faculty voices on diversity in academic medicine: perspectives from one school. Acad Med. 2008;83(8):781-786. doi: 10.1097/ACM.0b013e31817ec002.

5. Turner PL, Lumpkins K, Gabre J, Lin MJ, Liu X, Terrin M. Pregnancy among women surgeons: trends over time. Arch Surg. 2012;147(5):474-479. doi: 10.1001/archsurg.2011.1693.

6. Willett LL, Wellons MF, Hartig JR, et al. Do women residents delay childbearing due to perceived career threats? Acad Med. 2010;85(4):640-646. doi: 10.1097/ACM.0b013e3181d2cb5b.

7. Jolly S, Griffith KA, DeCastro R, Stewart A, Ubel P, Jagsi R. Gender differences in time spent on parenting and domestic responsibilities by high-achieving young physician-researchers. Ann Intern Med. 2014;160(5):344-353. doi: 10.7326/M13-0974

8. Guille C, Frank E, Zhao Z, et al. Work-family conflict and the sex difference in depression among training physicians. JAMA Intern Med. 2017;177(12):17661772. doi: 10.1001/jamainternmed.2017.5138.

9. DeFilippis EM. Putting the "She" in doctor. JAMA Intern Med. 2018;178(3):323-324. doi: 10.1001/jamainternmed.2017.8362.
10. Komaromy $M$, Bindman AB, Haber RJ, Sande MA. Sexual harassment in medical training. N Engl J Med. 1993;328(5):322-326. doi: 10.1056/ NEJM199302043280507.

11. Corbie-Smith G, Frank E, Nickens HW, Elon L. Prevalences and correlates of ethnic harassment in the U.S. Women Physicians' Health Study. Acad Med. 1999;74(6):695-701. doi: 10.1097/00001888-199906000-00018.

12. Amanatullah ET, Morris MW. Negotiating gender roles: gender differences in assertive negotiating are mediated by women's fear of backlash and attenuated when negotiating on behalf of others. J Pers Soc Psychol. 2010;98(2):256-267. doi: 10.1037/a0017094.

13. Babcock L, Maria PR, Vesterlund L. Why women volunteer for tasks that don't lead to promotions. Harvard Bus Rev. 2018.

14. Tsugawa Y, Jena AB, Figueroa JF, Orav EJ, Blumenthal DM, Jha AK. Comparison of hospital mortality and readmission rates for medicare patients treated by male vs female physicians. JAMA Intern Med. 2017;177(2):206-213. doi: 10.1001/jamainternmed.2016.7875.

15. Landel M. Why gender balance can't wait. Harvard Bus Rev. 2016.

16. Wolf TM, Randall HM, von Almen K, Tynes LL. Perceived mistreatment and attitude change by graduating medical students: a retrospective study. Med Educ. 1991;25(3):182-190. doi: 10.1111/j.1365-2923.1991.tb00050.x.

17. Wheeler DJ, Zapata J, Davis D, Chou C. Twelve tips for responding to microaggressions and overt discrimination: when the patient offends the learner. Med Teach. 2018:1-6. doi: 10.1080/0142159X.2018.1506097. 